\title{
К вопросу о «негосударственных участниках» механизма разрешения споров в рамках Всемирной торговой организации
}

Федорова М.П.*

В соответствии с положениями «Договоренности о правилах и процедурах разрешения споров» (ДСУ)' руюшего процесс разрешения споров в рамках Всемирной торговой организации $(\mathrm{BTO})^{2},-$ только члены этой организации могут использовать ее механизм для разрешения возникших между ними споров, связанных с их обязательствами, взятыми в рамках BTO $^{3}$. Однако возникает вопрос: могут ли в процессе урегулирования споров в каком-то качестве принимать участие, например, общественные организации, коммерческие юридические лица или физические лица?

Несмотря на то, что в отечественной литературе уже уделялось некоторое внимание механизму урегулирования споров в рамках ВТО, не все вопросы, связанные с данной сферой деятельности ВТО, были в достаточной мере освещены в работах российских авторов ${ }^{4}$. Одним из подобных вопросов является проблема участия в разрешении споров «негосударственных участников».

- Федорова Марина Павловна - аспирантка кафедры международного права СпбГУ.

' Understanding on rules and procedures governing the settlement of disputes- Приложение к Марракешскому договору. Также Dispute Settlement Understanding (DSU). Текст данного документа опубликован, например, в Documents Supplement to Legal problems of International Economic Relations, third edition, by John H. Jackson, William J. Davey, Alan O. Sykes. (West Group, 1995), а также доступен на официальном сайте ВТО www.wto.org.

${ }^{2}$ Договор о создании Всемирной торговой организации был подписан 15 апреля 1994 г. ${ }^{3}$ СТ. 1 ДСУ.

По состоянию на 4 апреля членами ВТО являются 146 государств. Членом ВТО таюке является Европейское Сообщество. Далее - члены ВТО.

${ }^{4}$ См., например: Григорян С.А. Международно-правовая система Всемирной торговой организации и интересы России. Диссертация на соискание ученой степени доктора юридических наук. М., 2000; Рогов С.Н. Системы разрешенкя международных торговых споров в ГАТТ и ВТО // МЖМП. 1998; Светланов А.Г., Шамсиев Х.Р., Ошноков А.Н. Россия и система Всемирной торговой организации (ВТО). Правовые аспекты. (Материалы научно-практической конференции, состоявшейся в Институте государства и права РАН 9 февраля 2000 г.) // Государство и право. 2000. № 7. С. 119. 
Начнем с понятийного аппарата. Подобные действующие лица обозначаются в литературе термином «private parties» или «nongovernmental parties», что можно перевести как «негосударственные участники». Закрепленного в документах определения негосударственного участника в контексте данной проблемы не существуег ставляется, однако, возможным установить путем анализа работ по данной теме, что под термином «рrivate parties» зарубежные ученыеправоведы в данном случае понимают физические лица, корпорации, негосударственные организации ${ }^{6}$, то есть любые лица, претендующие на участие в деятельности ВТО, но не являющиеся членами ВТО.

Так, профессор Чарновиц склоняется к мысли, что необходимо расширить участие негосударственных участников в деятельности ВТО. и в частности в процедуре разрешения споров ${ }^{7}$. По его мнению, деятельность ВТО не является достаточно прозрачной ${ }^{8}$. Профессор Шнайдер считает ${ }^{9}$. что основная проблема данной организации состоит В недостатке понимания со стороны широких слоев общества; практически только эксперты в области международной торговли разбираются в вопросах функционирования ВТО. Даниел Эсти полагает, что из-за недостаточной прозрачности деятельность ВТО как в материальной, так и в процессуальной области не является в полной мере справедливой $^{10}$. Более активное вовлечение негосударственных участников в деятельность ВТО помогло бы увеличить гласность" ' уменьшить

${ }_{5}^{5}$ процессе нагисания статьи автор ознакомился со значительным числом работ по данной теме, но ни в одной из них не было предложено определение «негосударственного участника», рассматривались лишь конкретные примеры потенциального или реального участия.

"Cм.напр.: Dukgcun Ahn. The Long Road Ahead: Dispute Settlement in the GATT/WTO (Ernst-Ulrich Petersmann, International Trade Law And The GATT/WTO Dispute Settlement System. The Hague: Kluwer Law International. xviii +704 pp. 1997.) 20 Mich. J. Int'l L. 1999. CH. 13. C. 415.

${ }^{7}$ См., например: Steve Charnovitz, указ. соч. С. 331.

${ }^{8} \mathrm{Cм}$., например: Steve Charnovitz, Participation of Nongovernmental Organizations in the World Trade Organization, 17 U. Pa. J. Int'l Econ. L. 1996. C. 333. См. также Danicl C. Esty, Linkages and Governance: NGOs at the World Trade Orgnization, $19 \mathrm{U}$. Pa. J. Int'l Econ. L. 1998. C. 715; Andrea K. Schneider, Individual Rights in International Trade Organizations, 19 U. Pa. J. Int'l Econ. L. 1998. C. 613.

${ }^{\circ} \mathrm{CM}$.: Andrea K. Schneider, Individual Rights in International Trade Organizations, $19 \mathrm{U}$. Pa. J. Int'l Econ. L. 1998. C. 613. См. также Steve Charnovitz, указ. соч. C. 333; Daniel C. Esty, указ. соч. С. 715.

${ }^{10}$ См.: Daniel C. Esty, указ. соч. C. 715.

"См.: G. Richard Shell, Participation of Nongovernmental Parties in the World Trade 
ореол загадочности вокруг ВТО, что, в свою очередь, уменышило бы критику и даже вызвало поддержку со стороны общественности ${ }^{12}$. Негосударственные участники, прежде всего негосударственные организации, представляют различные по уровню жизни слои общества в такой степени, в которой это не способны сделать государства ${ }^{13}$.

Оппоненты вовлечения негосударственных организаций в процесс принятия решений в ВТО считают, что в этом спучае указанные организации получили бы возможность влиять на выработку решения на национальном уровне, а затем, в случае неудачи - еще раз, на уровне $\mathrm{BTO}^{14}$. Другим аргументом является опасение влияния развитых государств и дискримннации интересов развиваюшихся стран в случае предоставлення больших возможностей общественным организациям, так как большинство их создаются в развитых странах.

Полагаю, что указанные выше аргументы, активно обсуждаюшиеся рядом зарубежных юристов-международников, носят не юридический, а скорее философско-социологический характер. Они не затрагивают недостатков деятельности ВТО юридического характера, а касаются проблем социальной справедливости. Между тем необходим юридический анализ возможного расширения участия негосударственных участников, в том числе негосударственных организаций, в деятельности ВТО.

Следует отметить, что идея допустить международные негосударственные организации к деятельности ВТО не нова. Так, в процессе разработки в 1946-1948 гг. положений Устава Международной торговой организации (МТO) ${ }^{15}$ предполагалось, что негосударственные

Organization: The Trade Stakeholders Model and Participation by Nonstate Parties in the World Trade Organization, 17 U. Pa. J. Int'l Econ. L. 1996. C. 376; Glen T. Schleyer, Power to the People: Allowing Private Parties to Raise Claims Before the WTO Dispute Resolution System, 65 Fordham L. Rev. 1997. C. 2295.

${ }^{2}$ Cм.: Daniel C. Esty. Указ. соч. C. 719.

${ }^{13}$ См.: Daniel C. Esty. Указ. соч. С. 718.

${ }^{14}$ Cм.: Daniel C. Esty. Указ. соч. C. 725. Контраргументом данному утверждению является утверждение, что в ряде случаев решения принимаются правительствами без учета всех возможных позиший. Более того, международный уровень обеспечивает более широкий спектр взлядов, которые могут служить материалом для размышления.

${ }^{15}$ В соответствии с первоначальным планом Бреттон-Вуддской системы, ее частью, наряду с Международным Валютным Фондом и Всемирным Банком, должна была стать Международная торговая организация (МТО). По инициативе ООН в 19461948 гт. были проведены переговоры по созданию МТО, в процессе которых была разработата Гаванская Хартия - Устав МТО. Ст. 87(2) Устава МТО предусматривает, 
организации будут играть значительную роль в $\mathrm{MTO}^{16}$. Это отражает первоначальную позицию создателей всемирной торговой системы, предусматривавшую участие в ней общественных организаций ${ }^{17}$. Следует, однако, отметить, что последуюшее отношение ГАТТ к этой идее было достаточно холодным ${ }^{18}$.

Часть 2 статьи V Договора о создании ВТО (1994) предусматривает, что Генеральный Совет может организовывать мероприятия для консультаций и сотрудничества с негосударственными организациями, занимающимися вопросами, относяшимися к деятельности ВТО. Однако данная статья не предусматривает участия негосударственных организаций в процедуре разрешения споров, а лишь обозначает возможность их сотрудничества с ВТО в целом ${ }^{19}$.

По мнению А. Шнайдер ${ }^{20}$, другая группа потенциальных негосударственных участников, состоящая из предприятий и физических лиц, также должна обладать определенными правами в рамках ВТО. Представляется, что приведенные выше аргументы за и против участия негосударственных организаций в деятельности ВТО справедливы и в отношении других негосударственных участников. Хотелось бы, однако, подчеркнуть, что негосударственные участники ни в коем случае не могут и не должны заменить государство при принятии решений во Всемирной торговой организации. ВТО -- это межгосударственная организация, и допускать негосударственных участников к процессу выработки и принятия решений нужно с большой осторожностью.

В настоящее время в разрешении спора ${ }^{21}$ могут участвовать государства-члены в качестве сторон или третьих сторон.

что “Организация может договариваться о консультациях и сотрудничестве с негосударственными организациями, занимаюшимися вопросами, затрагиваемыми Уставом MTO. ITO Charter, Article 87(2), reprinted in U.S. Department of State, Havana Charter for an International Trade Organization 1948. С. 110. См.: подроб̆неe Steve Charnovitz. Указ. соч. С. 338. См. таюже Paul Demaret, The Metamorphoses of the GATT: From the Havana Charter to the World Trade Organization, 34 Colum. J. Transnat"l L. 1995. C. 124.

${ }^{16}$ См.: Steve Charnovitz. Указ. соч. С. 338.

${ }^{17}$ См.: Steve Charnovitz. Указ. соч. С. 339. Следует, однако, отметигь, что другие теоретические возможные участники не упоминались.

${ }^{18}$ Там же.

${ }^{19} \mathrm{O}$ других негосударственных участниках речь, как и ранее, не идет.

${ }^{20}$ См., например: Andrea K. Schneider. Указ. соч. С. 589.

2' В механизме разрешения споров в рамках ВТО можно условно выделить следующие стадии: консультации, разреление спора с помошью групп по разрешению споpa, апельяционное обжалование, исполнение решения. 
Как следует из ст. 1 ДСУ, сторонами могут быть только государства - члены ВТО. Никакие негосударственные участники не могут выступать стороной в споре. Это означает, что даже юридическое лицо, находящееся на территории государства - участника ВТО, терпяшее колоссальные убытки ${ }^{22}$ от неправомерных в соответствии с обязательствами членов ВТО действий других государств-членов, не может инициировать против них процедуру разрешения спора в рамках ВТО. В таком случае оно должно обратиться к правительству своего государства с просьбой инициировать дело против иностранного государства - члена ВТО ${ }^{23}$.

Ряд авторов отмечают, что, так как именно деятельности негосударственных участников часто наносится вред несоблюдением иностранными государствами своих обязательств по ВТО, было бы справедливо предоставить им право инициировать рассмотрение спора в рамках $\mathrm{BTO}^{24}$. По мнению А. Шнайдер, торговые соглашения содержат набор прав негосударственных участников против государств. В самом деле, государства заключают торговые соглашения, чтобы поощрить торговлю «своих» предпринимателей с иностранными. Следовательно, полагает профессор Шнайдер, их участие в разрешении споров в рамках ВТО вполне оправданно 25 .

Профессор Шнайдер также исследует гроблему, заключающуюся в том, что государство - член ВТО не будет инициировать дело против самого себя. В таком случае, полагает она, предоставление права инициировать разбирательство в рамках ВТО негосударственным участникам сделает возможным даже инициирование дел против их собственного государства ${ }^{26}$. В качестве примера профессор Шнайдер приводит довод, что в течение последних пятидесяти лет негосударственные участники имекг право подавать иски в международные судебные учреждения ${ }^{27}$.

"2 Негосударственные участники в настоящее время являются активными участниками мировой торговли (See United States - Sections 301-310 of the Trade Act of 1974, WT/ DS152/R; (99-5454), 22 December, 1999, 7.73-7.76).

${ }^{23} \mathrm{C}$., например: Matt Schaefer, Are Private Remedies in Domestic Courts Essential for International Trade Agreements to Perform Constitutional Functions with Respect to SubFederal Governments?, 17 J. INTL. L. BU (winter 1996/spring 1997). C. 625. Мэтт Шефер пишет о контрольных полномочиях государства и продолжении практики, в соответствии с которой, по его мнению, сила имеет большее значение, чем право.

${ }^{24}$ См.: Glen T. Schleyer. Указ. соч. С. 2277; см. также Sung-joon Cho. Указ. соч. С. 347.

${ }^{25}$ Cм.: Andrea K. Schneider. C. 598-599.

${ }^{26} \mathrm{C}_{\mathrm{M} .:}$. Andrea K. Schneider C. 628.

${ }^{27}$ См.: Schneider. Указ. соч. С. 707. 
Полагаю, что А. Шнайдер слишком широко трактует положения соглашений ВТО. Эти положения адресованы членам ВТО, то есть носителями прав и обязанностей являются государства. Члены ВТО взяли обязательства по отношению к другим государствам-членам, а не по отношению ко всем лицам, ведущим предпринимательскую деятельность. Кроме того, в случаях, которые имеет в виду профессор Шнайдер, государства осознанно предоставили юридическим и физическим лицам возможность обратиться в международные судебные учреждения. Негосударственные участники в подобных случаях - лишь бенефициары. В случае ВТО государства не дали согласия на участие в процедуре разрешения споров в качестве стороны или третьей стороны негосударственных участников, следовательно, механизм разрешения споров в рамках ВТО остается исключительно межгосударственным форумом.

В некоторых государствах предусмотрен механизм обрашения негосударственных участников к своим правительствам с просьбой инициировать дело в рамках ВТО в связи с предполагаемыми нарушениями в области международной торговли со стороны иностранного государства. Так, подобная возможность предусмотрена Секциями 301-310 Акта о торговле (1974) США ${ }^{28}$. Следует, однако, отметить, что даже если процедура используется, это не гарантирует, что США предпримут действия, даже если жалоба имеет основания ${ }^{29}$.

Таким образом, возможные в настояџее время средства влияния негосударственных участников на инициирование спора в рамках ВТО достаточно ограниченны. Во-первых, они зависят от воли сотрудников государственных органов, уполномоченных принимать решение, инициировать ли разбирательство в рамках ВТО. Во-вторых, подобные процедуры предусмогрены не во всех государствах. В целом проблемой является то, что правительства могуг решить не иницинровать рассмотрение спора по политическим мотивам ${ }^{30}$, а постараться «за-

ix (19 U.S.C. $2411-2420(1994))$.

${ }^{29} \mathrm{C}$.: Jared R. Silverman. Multilateral Resolution over Unilateral Retaliation: idjudicating the Use of Section 301 Before the WTO, 17 U. Pa. J. Int'l Econ. L. 1996. 246 сн. 61; Richard O. Cunnigham \& Clint N. Smith, Section 301 and Dispute Settlement in the World Trade Organization: The Multilateral Trade Framework for the 21st Century and U.S. Implementing Legislation. Terence P. Stewart ed. 1996. C. 603-04.

${ }^{30}$ См.: Glen T. Schleyer. Указ. соч. С. 2277; см. также Yong Kim, The Beginning of the Rule of Law in the International Trade System despite U.S. Constitutional Constraints. 17 Mich. J. Int'l L. 1996. C. 988; Matt Schaefer, Указ. соч. C. 625. 
быть» или проигнорировать жалобы небольших предприятий ${ }^{31}$. Это является важным аргументом группы авторов, которые считают, что право инициировать разбирательство должно быть предоставлено всем, кому причиняется вред ${ }^{32}$.

Представляется, однако, что сложившаяся ситуация не может служить аргументом за предоставление частным лицам права инициировать рассмотрение спора в рамках ВТО. Необходимо совершенствовать неудовлетворительную, по мнению данных ученых, работу правительства, а не пытаться решить проблему, наделяя дополнительными правами негосударственных участников.

Критическое отношение к предложениям предоставить негосударственным участникам право инициировать рассмотрение спора с помощью механизма ВТО отнюдь не означает, что автор против всяческого их участия в процессе разрешения спора. Наоборот, их участие может оказаться очень полезным на стадиях рассмотрения дела группой по разрешению спора.

Так, в процедуре урегулирования спора возможно также участие эксперта или, что является предметом больших споров, amicus curiae ${ }^{33}$. Трудность здесь заключается в том, что Договоренность о правилах и процедурах разрешения споров не содержит подробных положений о процессе сбора и исследования доказательств. Данный документ ограничивается положениями ст. 13 о том, что группа может искать информацию «из любого источника» и может запросить необходимую информацию у любого органа или физического лица ${ }^{34}$, и положениями Приложения 4 к ДСУ о групле экспертов.

По-видимому, такая лаконичность Договоренности вызвана желанием предоставить больше свободьі группам по разрешению споров, обеспечить более гибкий подход к процедуре с целью наиболее эффективного достижения результата - урегулирования спора. В данном случае, однако, подобная сдержанность создателей ДСУ является причиной многих дискуссий. Попробуем разобраться в сложившейся ситуации.

${ }^{31}$ См.: Sung-joon Cho. GATT Non-Violation Issues in the WTO Framework: Are They the Achilles Heel of the Dispute Settlement Process? 39 Harv. Int'l L. J. 1998. C. 347; Andrea K. Schneider. Указ. соч. С. 707; Matt Schaefer. Указ. соч. С. 627.

${ }^{32}$ См.: Glen T. Schleyer. Указ. соч. С. 2277.

${ }^{33}$ Подробнее см. ниже.

${ }^{34}$ Если этот орган или физическое лицо находится под юрисдикцией государствачлена, группа обязана сначала уведомитъ об этом данное государство. (Ст. 13 ДСУ.) 
Рассмотрим возможности, предоставляемые ст. 13 Договоренности о правилах и процедурах разрешения споров. Из положений этой статьи, а также Приложения 4 к ДСУ следует, что негосударственные участники могут служить источником информации, запрашиваемой группой по разрешению спора; выступать в качестве источника информации для группы экспертов. Так как по данному вопросу споров не возникает, мы не будем на нем останавливаться.

Возможно ли участие негосударственных участников в качестве экспертов? Можно себе представить, что сотрудник экологической общественной организации будет приглашен в группу экспертов по спору, в котором заинтересована его организация. Однако в соответствии с п. 3 Приложения 4 к ДСУ эксперты должны действовать в личном качестве, а не как представители правительства своего государства или своей организации, поэтому в данном случае вряд ли можно говорить об участии самой организации в процессє разрешения спора.

Выше речь шла о случаях, когда информация запрашиеается группой по разрешению спора. Однако возникает вопрос: как быть в обратной ситуации, когда группа ничего не запрашивает, но какой-либо негосударственный участник, например негосударственная организация, представляет группе свой взгляд на рассматриваемую проблему, возможно, прилагаег документы. Подобное явление называется amicus curiae. В переводе с латинского это словосочетанне означает «друг суда» ${ }^{35}$. В Древнем Риме под атісі curiae понимались лица, не имевшие прямого интереса в пеле и представлявшие по собственнсй инициативе суду их соображения по вопросам права или сведения о фактических обстоятельствах дела. Смысл этого института состоял в том, чтобы помочь суду в затруднительной ситуации, предотвратить возможную ошибку. С течением времени этот бескорыстный подход изменился. В настоящее время «друзья суда» обычно действуют под влиянием своих интересов. Институт «друзей суда» используется в англоамериканской системе права, а романо-германской системе этот институт незнаком.

В Договоренности о правилах и процедурах разрешения споров ничего не сказано об amici curiae. Однако, ссылаясь на статью 13 ДСУ о праве «искать информацию», «друзья суда» неоднократно пытались представить свои взгляды в процессе разрешения спора ${ }^{36}$. Они широ-

"Black's Law Dictionary. Sixth edition. West Publishing Co. 1990. C. 82.

${ }^{36}$ До настоящего времени большинство петиций «друзей суда» были поданы негосу- 
ко интерпретировали расплывчатую формулировку статьи 13, утверждая, что «право искать информацию» предполагает и «право принимать информацию», даже если она не запрашивалась.

ДСУ не содержит подобного положения относительно Апелляционного органа. Рабочие Процедуры Апелляционного Обжалования (Рабочие Процедуры), созданные в соответствии с Арт. 17.9 ДСУ, также не регламентируют данный вопрос. Правило 16(1) Рабочих Процедур лишь предусматривает, что ссли возникает процессуальный вопрос, не урегулированный Рабочими Процедурами, то состав Апелляционного органа, слушающий данное дело, может разработать для данного дела собственную процедуру по этому вопросу, если она не противоречит положениям ДСУ, других соглашений ВТО и данных Правил.

В отсутствие четкой регламентации в тексте Договоренности может помочь практика разрешения споров. Хотя решения групп по разрешению споров и Апелляционного органа не являются прецедентами, они тем не менес служат важным источником информации о практике ВТО и нередко содержаг разъяснения по вопросу, нечетко или недоєтаточно подробно урегулированному в соглашениях ВТО.

Следует вцделить случай, когда сообщения «друзей суда» приобщаются к документам какой-либо из сторон. В таком случае этй документы принимаются к рассмотрению. Так, в деле United States-Import Prohibition of Certain Shrimp and Shrimp Products ${ }^{37}$ общественные организации хотели предоставить групле по разрешению спора свои материалы, и они смогли это сделать, но только приобщив их к материалам стороны в деле - США. Однако Апелляционный орган при рассмотрении данного дела указал, что группа имеет право самостоятельно решать, приобщать ли к делу материалы amici curiae, поданные на рассмотрение непосредственно группе ${ }^{38}$.

В отношении рассмотрения материалов amici curiae в апелляционной инстанции Апелляционный орган в одном из дел отметил, что он

дарственными организациями, несколько было подано промышленными объединениями и иссколько- профессорамн права, специализирующимися в этой области (Georg C. Umbricht. Amicus Curiae Briefs at the WTO.Journl of International Economic Law. 2001 . C. 778.

${ }^{37} \mathrm{CM}$. United States-Import Prohibition of Certain Shrimp and Shrimp Products (otyet группы по разрешению спора WT/DS58/R от Мау 15, 1998).

${ }^{38} \mathrm{CM}$ : United States-Import Prohibition of Certain Shrimp and Shrimp Products (orчeт Апелляционного органа WT/DS58/AB/R Para. 99-110.) 
вправе решать, принимать ли петиции аmici curiae ${ }^{39}$. В деле European Communities - Measure Affecting Asbestos and Products Containing Asbestos $^{40}$ Апелляционный орган разработал процедуру на основании Правила 16(1) Рабочих Процедур, в соответствии с которой «друзья суда» могли подавать свои материалы, однако ни один из полученных документов не был приобщен к делу Апелляционным органом4 ${ }^{41}$ Подобная позиция Апелляционного органа вызвала критику как со стороны amici curiae - за то, что материалы не были приобщены к делу, так и со стороны большинства государств - членов ВТО - за то, что вопрос о теоретической возможности принятия материалов «друзей суда» был решен положительно ${ }^{42}$.

Действительно, если досье «друга суда» подается отдельно, то есть не приобщается к документам государств-членов, тогда возникает ряд вопросов. Так, очевидно, что петиции «друзей суда» вынудят по крайней мере одну из сторон отвечать на положения, содержащиеся в поданном документе. Это требует значительного количества времени и может потребовать значительных затрат, причем отвечать надо будет на соображения лица, которое не имеет и не может иметь прав стороны в процессе разрешения спора. С другой стороны, петиции amicus curiae могут действительно содержать важную информацию.

В данном случае представляется обоснованной позиция, признающая, что из ст. 13 ДСУ вытекает право групп по разрешению спора решать вопрос, могут ли они принять петицию amicus curiae ${ }^{43}$, и в случае положительного ответа на этот вопрос принять ее. Действительно, разумно было бы полагаться на компетентность групп по разрешению спора и признать наличие у них права определять, в каком объеме и по каким вопросам они могут принимать петиции «друзей суда». Следует подчеркнуть, что речь идет о том, имеет ли право группа по урегулированию спора использовать материалы, предоставленные «друзьями суда», но ни в коем случае не о праве самих amici curiae

${ }^{39} \mathrm{CM}$. United States - Imposition of Counervailing Duties on Certain Hot-Rolled Lead and Bismuth Carbon Steel Products Originating in the United Kingdom. WT/DS138/AB/R or 7 июня 2000 г. Paras. 39-42.

${ }^{40} \mathrm{WT} / \mathrm{DS} 135 / \mathrm{AB} / \mathrm{R}$, от 5 апреля $2001 \mathrm{r}$.

${ }^{41}$ См.: Geert A. Zonnekeyn. The Appellate Body's Communication on Amicus Curiae Briefs in the Asbestos Case. An Echternach Procession? Journal of World Trade 35(3). 2001. C. 560. ${ }^{42} \mathrm{C}_{\text {M.: }}$ Georg C. . Umbricht. Amicus Curiae Briefs at the WTO. Journal of International Economic Law. 2001. C. 776.

${ }^{43} \mathrm{CM}_{\mathrm{M}}$ : Georg C. Umbricht. Amicus Curiae Briefs at the WTO. Journl of International Economic Law. 2001. C. 790. 
требовать принятия их документов группой. Данное утверждение справедливо и в отношении стадии апелляционного обжалования. Право требовать принятия документов группой по разрешению спора или Апелляционным органом имеют лишь члены ВТО, являюшиеся сторонами или третьими сторонами в споре, в то время как остальные члены ВТО, а тем более негосударственные лица, не обладают данным правом.

В отношении апелляционного обжалования следует подчеркнуть, что принимать к рассмотрению петиции amicus curiae на основании Правила 16(1) Рабочих Процедур возможно только в отношении конкретного дела, рассматриваемого Апелляционным органом. Следовательно, полезно было бы выработать единое правило, регламентирующее полномочия апелляционной инстанции в отношении документов amici curiae.

Представляется, что наилучшим решением было бы принятие четких правил посредством внесения дополнений в Договоренность о правилах и процедурах разрешения споров. До настоящего времени, однако, вопрос до конца не урегулирован и вызывает серьезные споры, отнимающие много времени, если подается петиция amicus curiae. 